\title{
Studying Dynamic Decision-Making in Construction Management using Adaptive Interactive Simulations
}

\author{
Pei Tang ${ }^{1}$, Amlan Mukherjee ${ }^{2}$ and Nilufer Onder ${ }^{3}$ \\ ${ }^{1}$ Graduate Research Assistant, Department of Civil and Environmental Engineering, \\ Michigan Tech., Houghton, MI 49931; email: ptang@mtu.edu \\ ${ }^{2}$ Assistant Professor, Department of Civil and Environmental Engineering, Michigan \\ Tech., Houghton, MI 49931; email: amukherj@mtu.edu \\ ${ }^{3}$ Associate Professor, Department of Computer Science, Michigan Tech., Houghton, \\ MI 49931; email: nilufer@mtu.edu
}

\begin{abstract}
:
Construction projects consist of multiple components such as on-site equipment resources, site layout, labor productivity, unexpected external events, and human decisions regarding resource allocation and activity rescheduling. Stochastic spatial and temporal interactions between those components result in dynamic complexity of construction projects. Decisions made in such dynamic task environments must consider both immediate impacts and long-term dynamic feedback. The objective of this research is to use the adaptive interactive simulation framework as an experimental test bed to study dynamics of decisions in construction scenarios. A simulation of a four story structural steel framed office building project was implemented within Interactive Construction Decision Making Aid (ICDMA) under five different decision strategies. Simulated construction performance data at each decision control point was collected and analyzed to compare the project dynamics resulting from five strategies, and those strategies were assessed as well. This research provides a perspective to study dynamics of decision making through interactive simulation while furthering the knowledge of effective decision making and the development of dynamic decision support systems in construction management.
\end{abstract}

\section{Introduction}

Decision-making in construction projects involves the management of multiple interrelated components such as site layout, critical equipment resources, labor productivity, unexpected events, resource allocation and rescheduling of activities. Uncertainty associated with each of these quantities, and the evolving relationships between them within the constraints of time and space are at the root of complexity in project management. Accounting for this complexity is critical to effectively plan for 
contingencies and test the usefulness of alternative decision-making strategies. However, predicting the consequences resulting from such complex behavior is difficult as they are often emergent within dynamic contexts. We argue that interactive adaptive simulations provide experimental platforms to test and compare the sensitivity of the project plans and estimates to alternative decision strategies and dynamic project complexities (Watkins 2008, Mukherjee et al. 2009). In this paper we propose and illustrate a methodology for studying dynamic complexity in construction management using interactive simulations as an experimental testbed.

This research uses relevant research in construction decision-making using System Dynamics, interactive simulation, and Markov decision process as a point of departure. The Dynamic Planning Methodology (DPM) uses concepts and methods in System Dynamics (SD) to account for dynamic feedbacks in the planning and control of fast-track construction projects. (Park and Pena-Mora 2009, Pena-Mora and Park 2001, Lee et al. 2006). Interactive simulations such as RiverWare (Biddle 1999) have also been used to aid real-time optimization of water resource system operations, for developing training programs for system managers and technicians, and in demonstrating system management alternatives (Cunningham and Amend 1984; Cunningham and Amend 1986). Among other methods, Ioannou (1989) uses Markov decision process for the solution of the risk-sensitive dynamic decision problems.

Each of these methods studies decision-making as a choice between decontextualized management strategies - accounting for uncertainties in long-term behavior, and models of cause-effect relationships. In this research we take the next step by developing a method that can be used to analyze and compare the evolution of outcomes associated with different decision-making strategies. A project specific implementation of a general-purpose interactive simulation environment the Interactive Construction Decision Making Aid (ICDMA) is used as an experimental platform to illustrate the method, specifically emphasizing the data collection and analysis process. The method is the contribution of this research - it can be used to gain insight into the behavior of specific simulated projects. The results of the analysis can be used to enhance the planning of contingencies during the preconstruction process - especially in the management of complex construction projects with limited historical precedence.

\section{ICDMA Simulation and Methodology}

ICDMA is a specific implementation of a general-purpose interactive simulation framework (Rojas and Mukherjee 2006, Watkins 2008). It simulates a construction project based on the as-planned schedule and costs as defined in a web-based database. The user of the simulation takes on the role of construction manager/ primary decision-maker whose goal is to complete the project on schedule and under budget. During the simulation run, the user is presented with random external events that force the simulated project to deviate from its original plan. The user has to respond to those events by making decisions on resource allocation. The consequences from the decisions result in new scenarios for the user to respond. This process continues until the completion of the simulated construction project. 


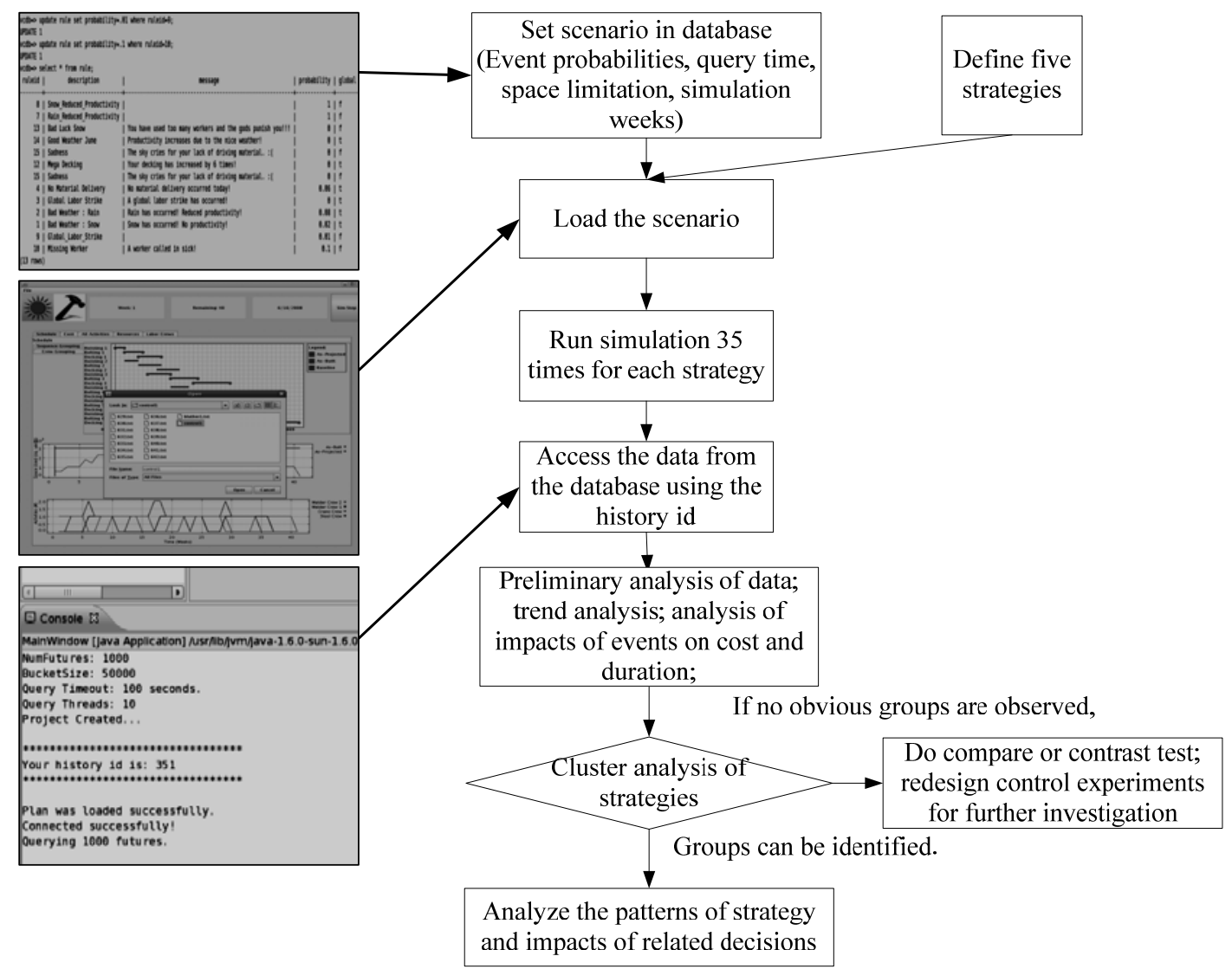

Figure 1 Flowchart of Methodology

ICDMA implements the construction of a four-storey structural steel framed office building that was built in real life. The simulation was based on the schedule and construction information documented by Daccarett and Mrozowski (1999). In previous work we have shown that the underlying construction models in ICDMA is capable of simulating the as-built performance of the actual project as described in Anderson et al. (2009). The research also illustrated the use of the querying algorithm, in ICDMA, to forecast likely project outcomes from any point in the project using current project information. A space of possible project outcomes consisting of future traces under varying conditions, constraints and decisions were generated and analyzed using a Monte Carlo sampling method. Each candidate in the future space is a complete simulation trace of the project. The actual project outcome was the most likely scenario in the space of possible outcomes.

In effect, the querying algorithm forecasts the likelihood of future scenarios and outcomes by querying a space of simulated project futures. In this paper, we take the next step in investigating the application of ICDMA and the querying algorithm to compare alternative decisions by statistically analyzing and clustering the simulated future outcome space. Specifically, a potentially problematic scenario is established and different control strategies to deal with its resolution are explored in an interactive simulation mode. The application of this research is during the preplanning and planning phases of complex construction projects. 
The scenario was set-up by simulating the office-building project to 14 days in the future. At this point, the project was behind schedule. External events expected in the project's future were rain (major weather), snow (extreme weather), labor strike, no material delivery, and worker sick. Their respective probabilities were set at 0.08 , $0.02,0.01,0.06$, and 0.10 . Hence, the probability it will rain is 0.08 each time the simulator is advanced by one time unit. In addition, the space capacity was set to 3,000 units. If the space occupied by the material exceeds this limitation, a space conflict event occurs. These probabilities are specific to the project at hand and the investigators using the simulation can choose appropriate values to reflect the circumstances of their projects.

Once the scenario is set up, decision strategies are established and the simulation is run in the interactive mode using each of the strategies for a period of concern. During the simulation run, the decision-maker is required to manage the project by making decisions that specifically adhere to the strategy under investigation. In this research the window of concern was considered to be 6 days from day 15 to day 21. Hence, the decision-maker was allowed to implement control measures adhering to each strategy 6 times, once at the end of each day (details on strategies and data collection follow). Thirty-five such simulations were carried out for each of the decision strategies. During the simulation construction performance data at each decision control point was collected and stored in a database, organized by the history ID of each simulation run. The data is analyzed to compare the project dynamics resulting from five strategies. Figure 1 presents a flow chart of the methodology discussed.

A decision strategy is defined as the guideline and direction that provide the basis for a family of decisions towards achieving a project outcome. Five strategies are defined and implemented in ICDMA in this paper. Future studies using this method could choose a different set of strategies to reflect the reality of the project being simulated. A control strategy is used to reflect baseline conditions and the other four strategies are chosen as alternative approaches to managing the project at hand. In this case, the control strategy aims at completing the project by adhering closely to a baseline decision sequence. The crash strategy tries to crash the schedule to save time. The reassign strategy aims to optimize the project by prioritizing activities on the critical path. The safety strategy aims at reducing the risks due to delayed material delivery by ordering materials ahead. The catch up strategy tries to catch up with the schedule when it falls behind. It is important to note that the strategies make no direct adjustments for bad weather, global strike, and material delivery failure. The strategies were coded to respond to the consequences of the events rather than to the occurrences of the events. Detailed descriptions of the guidelines provided by each of the decision strategies are shown in Table 1.

\section{Data Collection}

Data was collected at the end of each simulation time point. The categories of data collected include: (i) Outputs of the querying algorithm including a set of simulated future spaces (set size $=1000$ ) and a frequency distribution of final cost and duration outcomes of the simulated projects, and (ii) Metrics (as described below) defining the project status and specific decisions that were taken at the end of each decision control point. These data sets were collected after each of the 6 decision control 
points for 35 runs per decision strategy. Hence a total of $(6 \times 5 \times 35=) 1050$ data sets were collected.

\begin{tabular}{|c|c|c|c|c|}
\hline & $\begin{array}{c}\text { Labor\& } \\
\text { material } \\
\text { allocation }\end{array}$ & Policy on Space Conflict & Material policy & Labor policy \\
\hline $\begin{array}{l}\text { Control } \\
\text { Strategy }\end{array}$ & $\begin{array}{l}\text { Do not } \\
\text { crash. }\end{array}$ & $\begin{array}{l}\text { Reduce material inflow } \\
\text { uniformly on all activities. }\end{array}$ & $\begin{array}{c}\text { Do not order } \\
\text { materials ahead. }\end{array}$ & $\begin{array}{l}\text { Do not recruit } \\
\text { workers if they call } \\
\text { in sick. }\end{array}$ \\
\hline $\begin{array}{l}\text { Crash } \\
\text { Strategy }\end{array}$ & $\begin{array}{l}\text { Crash } \\
\text { critical } \\
\text { activity. }\end{array}$ & $\begin{array}{l}\text { Allocate the space from non } \\
\text { critical activities to the most } \\
\text { critical activity. }\end{array}$ & $\begin{array}{l}\text { Do not order } \\
\text { materials ahead; } \\
\text { Order more } \\
\text { material on the } \\
\text { most critical } \\
\text { activity. }\end{array}$ & $\begin{array}{l}\text { Recruit workers if } \\
\text { they call in sick; } \\
\text { Recruit more labor } \\
\text { on the most critical } \\
\text { activity; One crane } \\
\text { operator must be } \\
\text { ensured. }\end{array}$ \\
\hline $\begin{array}{l}\text { Reassign } \\
\text { Strategy }\end{array}$ & $\begin{array}{c}\text { Crash } \\
\text { critical } \\
\text { activities. }\end{array}$ & $\begin{array}{l}\text { Reduce material inflow } \\
\text { uniformly on noncritical } \\
\text { activities; Do not reduce that } \\
\text { on critical activities. }\end{array}$ & $\begin{array}{c}\text { Reassign } \\
\text { resources from } \\
\text { noncritical to } \\
\text { critical } \\
\text { activities; Never } \\
\text { order materials } \\
\text { ahead. }\end{array}$ & $\begin{array}{l}\text { Recruit workers if } \\
\text { they call in sick. }\end{array}$ \\
\hline $\begin{array}{l}\text { Safety } \\
\text { Strategy }\end{array}$ & $\begin{array}{l}\text { Do not } \\
\text { crash. }\end{array}$ & $\begin{array}{l}\text { Reduce material inflow to } \\
150 \% \text { of normal on critical } \\
\text { activities and uniformly on } \\
\text { noncritical activities; Reduce } \\
\text { uniformly if all are critical. }\end{array}$ & $\begin{array}{l}\text { Order materials } \\
\text { ahead on critical } \\
\text { activities as a } \\
\text { buffer. }\end{array}$ & $\begin{array}{l}\text { Recruit workers if } \\
\text { they call in sick. }\end{array}$ \\
\hline $\begin{array}{l}\text { Catch } \\
\text { Up } \\
\text { Strategy }\end{array}$ & $\begin{array}{c}\text { Crash } \\
\text { critical } \\
\text { activities. }\end{array}$ & $\begin{array}{l}\text { Reduce materials on non- } \\
\text { critical activities uniformly, } \\
\text { and never reduce material on } \\
\text { critical activities. }\end{array}$ & $\begin{array}{l}\text { Do not order } \\
\text { materials ahead; } \\
\text { Order more } \\
\text { material on the } \\
\text { most critical } \\
\text { activities. }\end{array}$ & $\begin{array}{l}\text { Recruit workers if } \\
\text { they call in sick; } \\
\text { Recruit more labor } \\
\text { on the most critical } \\
\text { activities; One crane } \\
\text { operator must be } \\
\text { ensured. }\end{array}$ \\
\hline
\end{tabular}

Table 1 Strategy Description

Description of the metrics collected from the simulation to describe the status of the project and the decisions taken at the end of each day are:

Labor data: (1) Number of laborers assigned per plan for each activity (unit=person); (2) number of workers who actually worked for each activity (unit=person).

Material data: (1) Number of materials assigned per plan to be installed (unit varies); (2) number of materials actually installed (unit varies); (3) number of materials not used and stored due to reduced productivity (unit varies).

Space data: (1) Space that has been used on site (unit=square yards).

Cost data: (1) As-planned labor cost (unit=\$); (2) as-built labor cost (unit=\$); (3) as-planned material cost (unit $=\$$ ); (4) as-built material cost (unit $=\$$ ); (5) as- 
planned indirect cost (unit=\$); (6) as-built indirect cost (unit=\$); (7) predicted cost for entire project (unit $=\$$ ).

Duration data: (1) Predicted duration for entire project (unit=day).

Activity data: (1) Activities that are being current - and schedule status.

Decision data: (1) Number of extra laborers recruited (unit=person); (2) actual number of materials that has been ordered (unit varies); (3) Percentage of schedule duration reduced; (4) Material and labor production rate in percentage work schedule and increased labor budget in hours and percentage; (5) Activity priorities; (6) Decision time to judge the project condition (unit=second); (7) Decision time to response to the events (unit=second).

Events data: (1) list of external events that occurred.

\section{Dynamic Decision Making Analysis}

This part describes how the data collected from interactive simulation can be used to study the dynamics of decisions specifically how the decisions for each of the five strategies influence long term behavior of the construction project.

Preliminary Data Analysis: For each strategy, 35 simulation runs are carried out. The average costs and durations of those 35 simulation runs from day 15 to day 21 reflect how the system responds to the strategies. Since the costs and durations are represented by the frequency distribution, their expectations are calculated by approximating the frequency distribution into a probability distribution. The expected value of predicted costs and duration from day 15 to day 21 under five strategies are shown in Figures 2 and 3.

The horizontal axis in Figure 2 and 3 is the simulation time (unit=day), and the expected values of predicted duration and costs are on the vertical axis (unit $=\$$ for cost and unit=day for duration). Figure 2, shows that as the simulator advances, the predicted costs and durations for the entire project decrease except for decisions made using the reassign strategy. Two explanations are offered for this general declining trend in cost and duration. One is that the temporal constraints (including activity relationships in the simulated project) are more complicated towards the beginning than towards the end of the project. As all decisions have a cascading impact on the schedule, the project status near the completion is less affected as, more activities are temporally connected earlier in the schedule. The sooner the decisions are made and events occur, the greater the impacts on the temporal constraints, resulting in a higher costs and longer durations. The second reason is that the occurrence of external events decreases as the project evolves. As the remaining duration is reduced, the probability of external events in future reduces, thus reducing the cost to mitigate the impacts.

Comparing cost data between control strategy and safety strategy indicates that ordering the materials ahead could help reduce both project cost and duration. From Figure 2, it can be seen that the control strategy is less cost efficient than the safety strategy. The difference between the two strategies is that material is ordered ahead under safety strategy. Without materials in stock, the project would be delayed in case of material delivery failure. Figure 3 also illustrates that predicted remaining durations after each day under safety strategy are shorter than that under control strategy. 
Increasing resource input into more than one critical activity at one time seems to be more efficient in minimizing cost and duration. The differences in those two strategies are that only one critical activity could be crashed under crash strategy while more than one activity could be crashed under the catch up strategy. In Figures 2 and 3, the predicted cost and duration under catch up strategy is lower and shorter than that under crash strategy. However, the following cluster analysis shows that this assumption depends on how the non-critical activities are implemented.

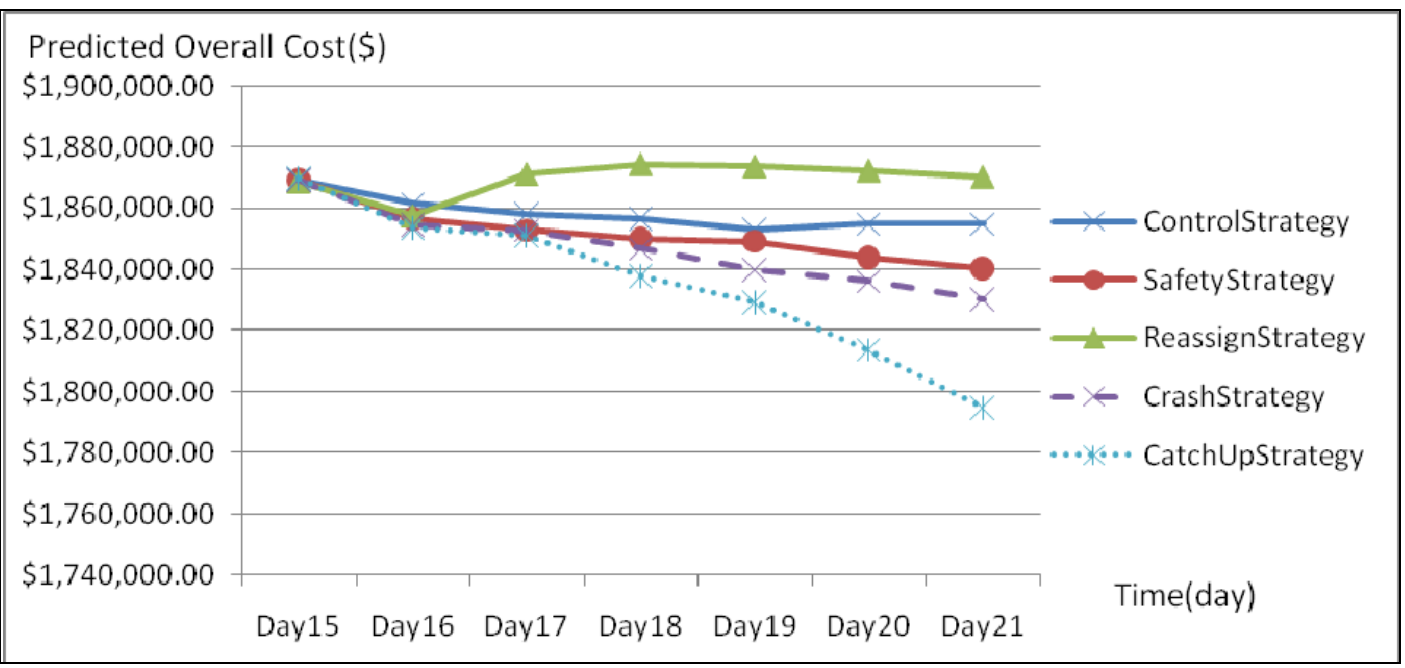

Figure 2 Predicted Project Cost from Day 15 to Day 21

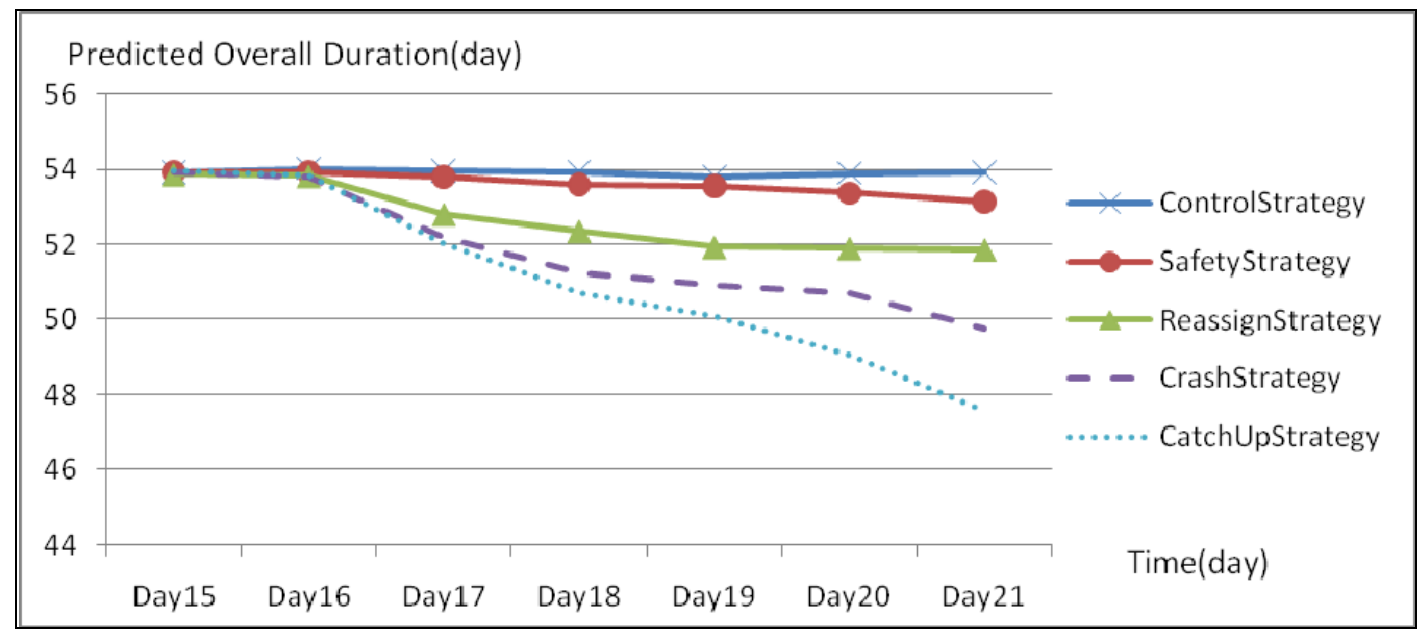

Figure 3 Predicted Project Duration from Day 15 to Day 21

Studying strategy groups might be meaningful because similar outcomes might have common behavior or mechanisms that drive them. From the project expenditures and durations under different strategies, we can see that control strategy, safety strategy, and crash strategy have similar outcomes and can be considered to be in the same group in Figure 2. Catch up strategy and reassign strategy offer distinctly different trends. In Figure 3, control strategy and safety strategy can be considered in 
the same group. Catch up strategy and crash strategy offer different trends. It is difficult to classify the reassign strategy only based on Figure 3. Hence, the next step in the analysis is to conduct a cluster analysis to group strategies with similar outcomes.

Hierarchical Cluster Analysis: Cluster analysis is an exploratory data analysis tool aimed at sorting different objects into groups so that the degree of association between two objects is maximal if they belong to the same group (Aldenderfer and Blashfield, 1984). Cluster analysis is used to discover how outcomes from the simulation form associative groups. We used the Statistical Package for the Social Sciences (SPSS) to implement cluster analysis. The variables used on the cluster analysis were the expected values of the predicted cost and duration for the project from day 15 to day 21. The expected costs predicted in each day are chosen as variables and the cases are labeled by strategies.

A dendrogram was chosen to illustrate the forks between each of the simulation runs to indicate formation of coherent clusters. Ward's method was used to create clusters because it minimizes the sum of squares of any pair of clusters to be formed at a given step. (Aldenderfer and Blashfield, 1984). Z-score was chosen to standardize the data to eliminate the affects of the variance of variables.

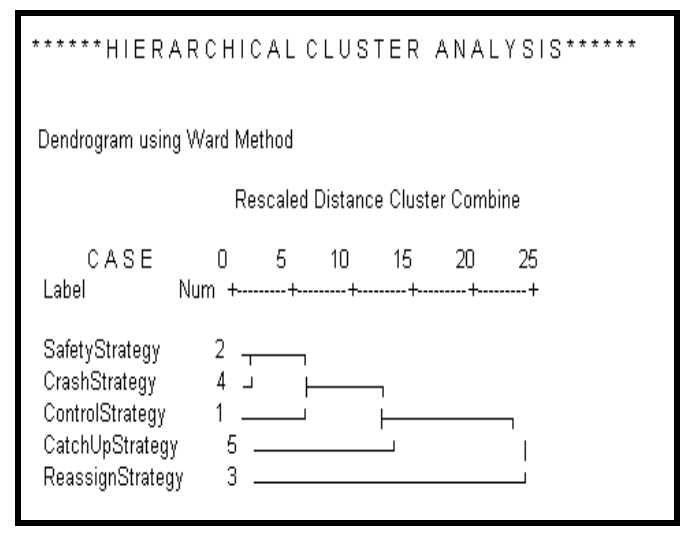

Figure 4: Cluster result with respect to cost

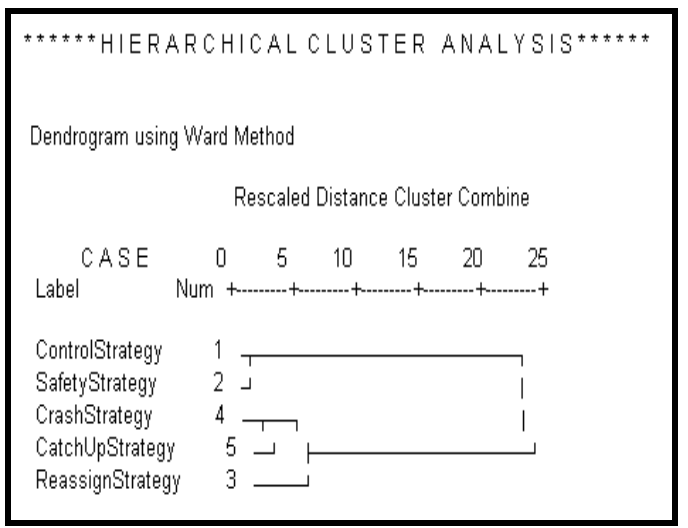

Figure 5: Cluster result with respect to duration

The dendrogram in Figure 4 was created using final project cost outcome. The safety and crash strategies are the most similar and are in one group. The control strategy is closer to that group than catch up strategy and the reassign strategy. Thus, the first group includes safety strategy, crash strategy, and control strategy while the catch up strategy and the reassign strategy are in the second and third group as what we have predicted from Figure 2. The dendrogram in Figure 5 was created using final project duration. The strategies can be grouped into two clusters. The first cluster includes control strategy and safety strategy, and the second cluster includes crash strategy, catch up strategy, and reassign strategy. Within the second cluster, two subclusters emerge. The first sub-cluster consists of the crash strategy and the catch up strategy, and the second sub-cluster consists of the reassign strategy. The sub-clusters provide a more nuanced perspective on the differences between the strategies. 
Comparisons between those groups from duration data indicate that increasing labor and resource input on the critical activity reduces duration, even if its impacts on cost may vary. Critical variances between the first strategy group consisting of the control strategy and safety strategy, and the second strategy group consisting of the other three strategies, are that the later group has more labor and resource inputs on the critical activity. From Figure 2 and 3, the second group is more efficient in minimizing duration than group one.

However, whether a strategy is cost effective depends on how many noncritical activities are completed. The differences between the first strategy sub-cluster and the second strategy sub-cluster under the second strategy cluster in Figure 5 are that noncritical activities are impacted when resources are moved from noncritical to critical activities under the second strategy sub-cluster, while noncritical activities are hardly impacted under the first strategy sub-cluster. These differences show that increasing labor and resource inputs on critical activities is cost effective, as long as labor and material inputs into noncritical activities are not ignored. When the labor and material inputs are moved from noncritical activities to critical activities, critical activities are crashed while increasing the duration of noncritical activities. Beyond a threshold, the durations of the non-critical activities increase to the point where they become critical, incurring more indirect cost. This explains why the trend of cost under the reassign strategy is rising in Figure 2, and this is in the third strategy group in Figure 4.

\section{Conclusions and Future Work}

Preliminary data analysis together with cluster analysis indicates that it would be efficient to manage construction projects by (a) ordering the materials ahead; (b) increasing labor and material input on all the critical activities while ensuring the labor and material inputs into noncritical activities as well. While these results are specific to the project investigated, they reflect measures that contractors often use in practice, indicating the feasibility and usefulness of the proposed methods in studying the dynamics of decision-making. It is also indicated that it is important to study the overall project specific effects of fixed strategies and a good strategy will be a combination of the fixed strategies.

It is important to note that this paper provides only a preliminary investigation of the data. Further statistical analysis will need to be carried out to understand the time lags over which decisions have impacts. In addition, future research will provide enhancements to the simulation so that it can represent adaptive bottom-up influences resulting from labor and equipment interactions on site. These influences are critical to investigating and identifying dynamic feedbacks associated with alternative decision strategies. Future work also includes studying the similarities and differences between simulation results and the expectations according to general principles in construction management.

Finally, while this research is presented in the context of construction decision-making, the platform provided and the method proposed is extensible and can be applied to study decision-making in other temporally and spatially constrained dynamic task environments.

\section{Acknowledgements}


This work is based upon work supported by the National Science Foundation under Grant No. SES-0624118. Any opinions, findings and conclusions or recommendations expressed in this material are those of the authors and do not necessarily reflect views of the National Science Foundation.

\section{References}

Aldenderfer, M.S. and Blashfield, R.K.(1984), Cluster Analysis, Beverly Hills, Calif.

Anderson, G.R.; Mukherjee, A.; Onder, N.(2009), Traversing and Querying Constraint Driven Temporal Networks to Estimate Construction Contingencies, Automation in Construction, Vol. 18, Issue 6, pp 798-813.

Biddle, S.H. (1999), RiverWare Applications at TVA, Proceedings of Waterpower Conference 1999, section 22, chapter 2.

Cunningham, A.B. and Amend, J.R. (1984), Water Management Using Interactive Simulation, Journal of Water Resource Planning and Management, Vol. 110, Issue 3, pp. 310-322.

Cunningham, A.B. and Amend, J.R. (1986), Interactive Simulation of Water Resource Systems, Journal of Water Resource Planning and Management, Vol. 112, Issue 3, pp. 326-338.

Daccarett, V. and Mrozowski T.(1999), American Institute of Steel Construction, AISC digital library: Construction management of steel construction Available via, http://www.aisc.org/content.aspx?id=21250, accessed October 26, 2009.

Ioannou, P.(1989), Dynamic Probabilistic Decision Processes, Journal of Construction Engineering and Management, Vol. 115, No. 2, pp. 237-257.

Lee, S.H.; Peña-Mora, F.; Park M. (2006), Dynamic Planning and Control Methodology for Strategic and Operational Construction Project Management, Automation in Construction, Vol. 15, Issue 1, pp 84-97.

Mukherjee, A.; Onder, N.; Tebo, C.; Kaaikala, K.(2009), An Experimental Framework to Analyze Alternative Decision-making Strategies Using Situational Simulation in Construction Management, Winter Simulation Conference 2009, ACM/IEEE/INFORMS (SIGSIM), New York, NY

Park, M., and Peña-Mora, F. (2000), Dynamic Planning and Control of Large Scale Infrastructure Projects, Proceedings of the Eighth International Conference in Computing in Civil and Building Engineering, ASCE Press, pp. 930-939.

Peña-Mora, F., and Park, M. (2001), Dynamic Planning for Fast-Tracking Building Construction Projects, Journal of Construction Engineering and Management, Vol. 127, No. 6, pp. 445-456.

Rojas, E. and Mukherjee, A. (2006). A Multi-Agent Framework for GeneralPurpose Situational Simulations in the Construction Management Domain, Journal of Computing in Civil Engineering, 20(6), pp 1-12.

Watkins, M.T.(2008), Developing Top-down and Bottom-up Simulated Environments for Decision-making Research in Construction Project Management, M.Sc. Thesis, Computer Science Department, Michigan Technological University, pp 14. 